\title{
Role of p21CIP1 as a determinant of SC-560 response in human HCT116 colon carcinoma cells
}

\author{
Eunmyong Lee ${ }^{1}$, Moon-Kyung Choi ${ }^{2}$, \\ Inn-OC $\mathrm{Han}^{3}$ and Soo-Jeong Lim ${ }^{1,4}$
}

${ }^{1}$ Department of Bioscience and Biotechnology

Sejong University

Seoul 143-747, Korea

${ }^{2}$ Research Institute National Cancer Center

Goyang, Gyeonggi-do 410-769, Korea

${ }^{3}$ Department of Physiology and Biophysics

Inha University, College of Medicine

Incheon 402-751, Korea

${ }^{4}$ Corresponding author: Tel, 82-2-3408-3767;

Fax, 82-2-3408-3334; E-mail, sjlim@sejong.ac.kr

Accepted 10 May 2006

Abbreviations: COX, cyclooxygenase; ROS, reactive oxygen species

\begin{abstract}
SC-560, a strucutral analogue of celecoxib, induces growth inhibition in a wide range of human cancer cells in a cyclooxygenase (COX)-independent manner. Since SC-560 suppresses the growth of cancer cells mainly by inducing cell cycle arrest, we sought to examine the role of $\mathrm{p} 21 \mathrm{CIP1}$, a cell cycle regulator protein, in the cellular response against SC-560 by

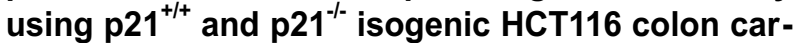
cinoma cells. In HCT116 $\left(\mathrm{p}^{2} 1^{+/+}\right)$cells, SC-560 dose-dependently induced growth inhibition and cell cycle arrest at the $\mathbf{G} 1$ phase without significant apoptosis induction. SC-560-induced cell cycle arrest was accompanied by upregulation of p21CIP1. However, the extent of SC-560-induced accumulation at the $\mathbf{G 1}$ phase was approximately equal in the p2 $1^{+/+}$and the $\mathrm{p} 21^{-/ /}$cells. Nonetheless, the growth inhibition by SC-560 was increased in $\mathrm{p}^{2} 1^{-/}$cells than p21 ${ }^{\text {t/ }}$ cells. SC-560-induced reactive oxygen species (ROS) generation did not differ between $\mathrm{p} 21^{t /+}$ and p21 $1^{-1-}$ cells but the subsequent activaton of apoptotic caspase cascade was more pronounced in $\mathrm{p} 21^{--}$cells compared with $\mathrm{p} 21^{+/+}$cells. These results suggest that p21CIP1 blocks the SC-560-induced apoptotic response of HCT116 cells. SC-560 combined with other therapy that can block p21 CIP1 expression or function may contribute to the effective treatment of colon cancer.
\end{abstract}

Keywords: apoptosis; caspase; cell cycle; cyclin-dependent kinase inhibitor p21; growth inhibitors; HCT116 cells; SC 560

\section{Introduction}

The cell cycle in eukaryotes is controlled, at least in part, by a family of protein kinase complexes wherein each complex is composed of a catalytic subunit, the cyclin-dependent kinase (CDK), and its essential regulatory subunit, the cyclins. The cyclinCDK complexes are subject to inhibition via binding to a class of proteins known as the CDK inhibitors, such as p21 (WAF/CIP1), resulting in blockade of cell cycle progression. p21CIP1 is also able to bind proliferating cell nuclear antigen (PCNA) as well as $\mathrm{CDK}$, thereby inhibiting the cell cycle progression.

In addition to being an inhibitor of cell cycle progression, p21CIP1 also plays a role in cellular senescence, differentiation and apoptosis by interacting with a number of key regulatory proteins (Fotedar et al., 2004). For example, p21CIP1 is capable of being complexed with procaspase-3 and blocking its processing and activation, leading to protecting cells from apoptosis (Suzuki et al., 1998). p21CIP1 can also negatively regulate other apoptosisrelated proteins such as stress-activated protein kinase (SAPK) to inhibit apoptosis (Dotto, 2000). On the other hand, p21CIP1 can be cleaved by caspase-3-like proteases to produce a truncated protein that lacks the $\mathrm{C}$-terminus and can no longer bind PCNA, thereby converting the cell response from growth arrest to apoptosis (Prabhu et al., 1996; De Schepper et al., 2003). Therefore, p21Cip1 plays a protective or promoting role in apoptotic cellular response depending on the cellular context and the type of apoptotic stimuli (Gorospe et al., 1997; Wang et al., 1999; QinNg, 2001; Qiao et al., 2002).

SC-560 (5-(4-chlorophenyl)-1-(4-methoxyphenyl)-3trifluoromethylpyrazole) is a structural analogue of celecoxib, a well-known cyclooxygenase (COX) inhibitor. Recent studies showed that SC-560 inhibited the in vivo proliferation of colon and breast cancer cells to an extent similar to that observed with celecoxib and its anticancer effect appeared to be mediated through a mechanism independent from COX (Grosch et al., 2001; Kundu et al., 2002). Since SC-560 exerts its anticancer effects mainly by inducing cell cycle arrest, we sought to investigate the 
putative role of $\mathrm{p} 21 \mathrm{CIP} 1$ in mediating the SC-560 effects. By using $\mathrm{p} 21^{+/+}$and $\mathrm{p} 21^{-/-}$isogenic HCT116 cell lines, we show here that p21CIP1 is not crucial in SC-560-induced G1-phase arrest, but it plays an important role in protecting cells from apoptotic cell death subsequent to SC-560 treatment.

\section{Materials and Methods}

\section{Cell lines and reagents}

Wild-type HCT116 human colon carcinoma cells $\left(\right.$ HCT116/WT p21 ${ }^{+/+}$), which express normal p21CIP1, and a derivative in which both p21CIP1 alleles have been deleted through homologous recombination (HCT116/p21 $1^{--}$) were kindly provided by B. Vogelstein (Johns Hopkins University, Baltimore, MD) (Waldman et al., 1995), and immunoblots confirmed the expected lack of expression of p21CIP1. Cells were cultured in RPMI 1640 medium supplemented with $100 \mathrm{u} / \mathrm{ml}$ penicillin/streptomycin and $10 \%$ heatinactivated FBS (Hyclone, Logan, UT) and $100 \mathrm{u} / \mathrm{ml}$ penicillin/ streptomycin. All cells were grown in incubators in a humid atmosphere of $95 \%$ air $5 \%$ $\mathrm{CO}_{2}$.

$2^{\prime}, 7^{\prime}$-Dichlorodihydrofluorescein diacetate (DCFHDA) was purchased from Molecular Probes (Eugene, OR). SC-560 was purchased from Cayman Chemicals (Ann Arbor, MI). 3-(4,5-dimethylthiazol-2-yl)2,5-diphenyltetrazolium bromide (MTT) and antibodies to human $\beta$-actin were purchased from Sigma (St. Louis, MO). Antibodies to human p21CIP1 and p27Kip1 were obtained from Upstate Cell Signaling Solutions (Lake Placid, NY), and antibodies to cleaved caspase-3 were obtained from Cell Signaling (Beverly, MA).

All other chemicals were reagent grade and used without further purification.

\section{Cell growth and viability assay}

Cells were seeded in 96-well plates in $0.1 \mathrm{ml}$ of media supplemented with $10 \%$ FBS. On the following day the cells were treated with SC-560. SC-560 was dissolved in dimethyl sulfoxide at 100 $\mathrm{mM}$. Treatment solutions were made by serial dilution in growth medium. Control and treated cultures received the same amount of dimethyl sulfoxide (DMSO). Cell growth and viability were measured after $48 \mathrm{~h}$ using MTT, as described previously (Kang et al., 2005). The formation of formazan crystals by active mitochondrial respiration in cells was determined using a microplate spectrophotometer (BioTek, Winooski, VT) after dissolving the crystals in DMSO.

\section{Immunoblotting}

Cells were removed from the plates by scraping, washed twice with phosphate-buffered solution (PBS), and suspended in lysis buffer $(150 \mathrm{mM} \mathrm{NaCl}$, $10 \mathrm{mM}$ Tris, $0.2 \%$ Triton X-100, 0.3\% NP-40, 0.2 $\mathrm{mM} \mathrm{Na}_{3} \mathrm{VO}_{4}$, and protease inhibitor mixture [Roche Diagnostics Mennheim, Germany], $\mathrm{pH}$ 7.4) on ice for 15-30 min. Aliquots of cell lysates containing equal amounts of protein were denatured in SDS-reducing buffer by boiling for $5 \mathrm{~min}$, resolved on SDS-polyacrylamide gels, and transferred to nitrocellulose membranes. The resulting blots were blocked with $5 \%$ non-fat dry milk and incubated with specific primary antibodies. The blots were subsequently incubated with appropriate peroxidase-conjugated secondary antibodies and developed with ECL reagent (Amersham, Arlington Heights, IL) according to the manufacturer's protocol.

\section{Flow cytometry for the determination of cell-cycle distribution and apoptosis}

After treatment, cells were harvested, washed, fixed in $80 \%$ ethanol for $30 \mathrm{~min}$, and resuspended in PBS (pH 7.4) containing $0.1 \%$ Triton $X-100,5 \mu \mathrm{g} / \mathrm{ml}$ propidium iodide, and $50 \mu \mathrm{g} / \mathrm{ml}$ ribonuclease $A$ for DNA staining. The cell-cycle distribution was analyzed using FACScan (Becton-Dickinson, San Jose, CA) and Modfit 3.0 (Verity Software, Topsham, ME) cell-cycle analysis software. The percentage of apoptotic cells was assessed by calculating the percentage of cells in the sub-G1 phase (Darzynkiewicz et al., 1992).

\section{Apoptosis ELISA assay}

Histone-associated DNA fragments were quantified using a photometric enzyme immunoassay using Cell Death Detection ELISA ${ }^{\text {plus }}$ (Roche Applied Bioscience Mennheim, Germany) following the manufacturer's protocol.

\section{ROS-generation assay}

Non-fluorescent DCFH-DA, hydrolyzed to DCFH inside cells, yields highly fluorescent DCF in the presence of intracellular $\mathrm{H}_{2} \mathrm{O}_{2}$ and related peroxides. Therefore, the DCF fluorescence intensity is proportional to the amount of $\mathrm{H}_{2} \mathrm{O}_{2}$ formed intracellularly (Zang et al., 2001; Kang et al., 2004).

After treatment, the cells were harvested, washed twice with PBS, resuspended in serum-free medium, and incubated with $5 \mu \mathrm{M}$ DCFH-DA for $15 \mathrm{~min}$ at $37^{\circ} \mathrm{C}$. The cells were washed with ice-cold HEPES/ saline and placed on ice, and cell fluorescence was measured by flow cytometry using FACS calibur (FACSCalibur, BD Biosciences Mississanga, Cana- 


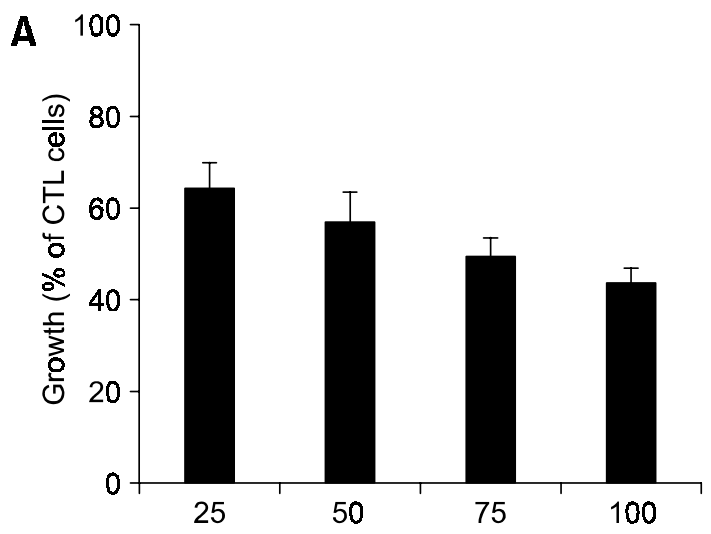

C

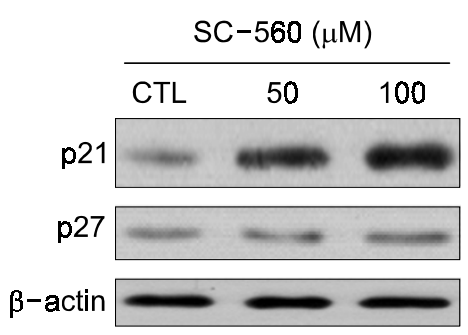

B

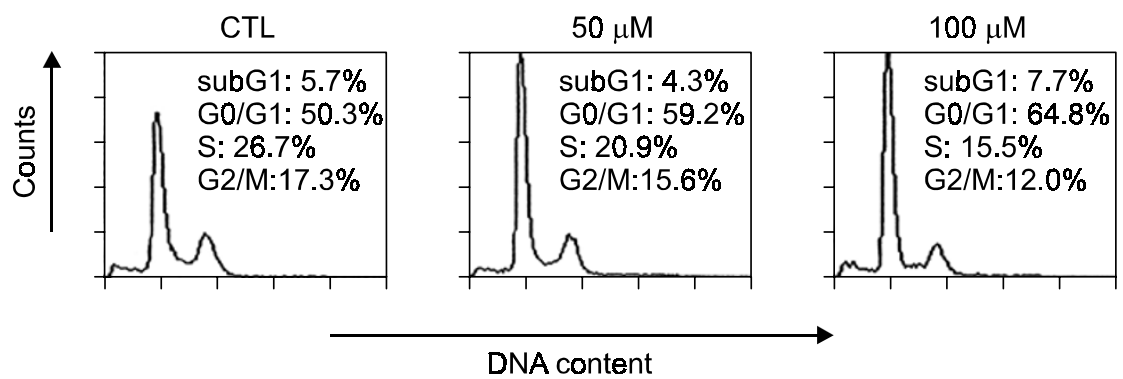

Figure 1. SC-560 induced growth suppression in HCT116 $\left(\mathrm{p} 21^{+/+}\right)$cells mainly by inducing cell cycle arrest at $\mathrm{G} 1$ phase. (A) Cells were plated at $5 \times 10^{3}$ cells/well in 96 -well plates with appropriate media containing $5 \% \mathrm{FBS}$ and, after $24 \mathrm{~h}$, were incubated with $0-100 \mu \mathrm{M} \mathrm{SC}-560$ for $48 \mathrm{~h}$. Cell growth and viability were determined by an MTT assay, as described in the text. Results are representative data of at least two independent experiments and are expressed as percentage growth (mean $\pm \mathrm{SD}$ ) relative to control (DMSO)-treated cells. (B) Representative FACS profile for SC-560-induced alterations to the cell-cycle distribution following treatment of HCT116 $\left(\mathrm{p} 21^{+/+}\right)$cells with vehicle alone (control) or with 50 or $100 \mu \mathrm{M} \mathrm{SC}-560$ for $24 \mathrm{~h}$. (C) SC-560 treatment induced the upregulation of

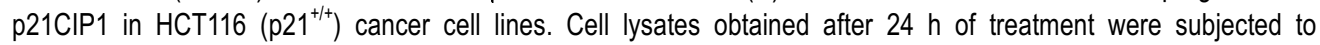
immunoblotting with appropriate antibodies. Immunoblotting with an antibody to $\beta$-actin was used to ensure equal loading of proteins in each lane (bottom panel).

da). As a positive control, cells were treated with $\mathrm{H}_{2} \mathrm{O}_{2}$ and processed for ROS detection.

\section{Statistical analysis}

Statistically significant differences between values obtained under different experimental conditions were determined using two-tailed unpaired Student's $t$-tests.

\section{Results and Discussion}

\section{SC-560 effect in HCT116/WT cells}

When we treated HCT116/WT $\left(\mathrm{p} 21^{+/+}\right)$cells with increasing doses of SC-560 for $48 \mathrm{~h}$, we found that SC-560 dose-dependently inhibited the growth of HCT116 cells (Figure 1A). Next we carried out cell cycle analysis to investigate whether the SC-560- induced growth inhibition was associated with cell cycle arrest or apoptosis induction. After $24 \mathrm{~h}$ treatment, SC-560 at 50 and $100 \mu \mathrm{M}$ caused a dosedependent accumulation of HCT116 cells at the G1 phase (Figure 1B). The sub-G1 phase population, corresponding to apoptotic cells, was only slightly increased in cells treated with $100 \mu \mathrm{M} \mathrm{SC}-560$ (Figure 1B). It suggests that SC-560 suppressed the growth of HCT116 cells mainly by inducing cell cycle arrest, in consistent with earlier studies (Kundu et al., 2002). Cell cycle arrest by SC-560 was accompanied by an increase in the expression of p21CIP1 protein in HCT116 $\left(\mathrm{p} 21^{+/+}\right)$cells. In contrast, the expression of p27KIP1, another CDK inhibitor, was not affected by SC-560 treament (Figure 1C). It suggests that SC-560 induces G1 arrest through a mechanism involving p21CIP1 upregulation in HCT116 cells. 


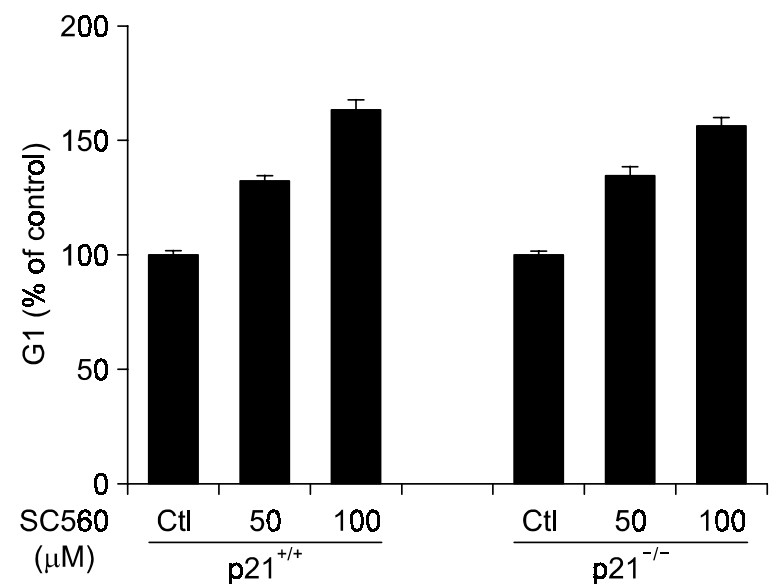

Figure 2. SC-560 dose-dependently induced the accumulation of cells at the $\mathrm{G} 1$ phase in HCT116 cancer cells regardless of p21CIP1 expression status. Following $24 \mathrm{~h}$ treatment with SC-560 in HCT116 $\left(\mathrm{p} 21^{+/+}\right)$and HCT116 (p21 $\left.{ }^{-1 /}\right)$ cells, the cell cycle distribution was determined by FACS analysis. Results are representative data of three independent experiments and are expressed as percentage cell accumulation (mean $\pm \mathrm{SD}$ ) relative to control (DMSO)-treated cells.

\section{SC-560 effect on the cell cycle of $\mathrm{p} 21^{1 /+}$ and $\mathrm{p} 21^{-1-}$ cells}

To investigate the role of p21CIP1 in mediating cell cycle arrest following SC-560 treatment, we compared the SC-560 effect on the cell cycle distribution of HCT116 $\left(\mathrm{p} 21^{+/+}\right)$and their isogenic $\mathrm{p} 21^{-/-}$ derivative cells. The extent of SC-560-induced accumulation at the $\mathrm{G} 1$ phase was approximately equal in the $\mathrm{p} 21^{+/+}$and the p21 $1^{-1-}$ HCT116 cells (Figure 2). These data imply that $\mathrm{p} 21 \mathrm{CIP} 1$ may not be essential in the SC-560-induced cell-cycle arrest at the G1 phase.

\section{SC-560 effect on the growth of $\mathrm{p} 21^{+/+}$and $\mathrm{p} 21^{-/}$cells}

Since the major cellular response against SC-560 was cell cycle arrest in HCT116 $\left(\mathrm{p} 21^{+/+}\right)$cells, we expected that the extent of growth inhibition induced by SC-560 would be similar in $\mathrm{p} 21^{+/+}$and $\mathrm{p} 21^{-/ /}$cells. However, we found that SC-560 treatment led to significantly increased growth suppression in $\mathrm{p} 21^{-1-}$ cells compared with p21 $1^{+++}$cells (Figure 3 ), particularly at doses higher than $50 \mu \mathrm{M}$. These data imply that p21CIP1 may be involved in protecting HCT116 cells from SC-560-induced growth inhibition.

\section{Effect of p21CIP1 on the ROS generation induced by SC-560}

Oxidative stress is one of major external factors, causing cell cycle arrest and/or apoptotic cell death depending on the strength and duration (Davies et

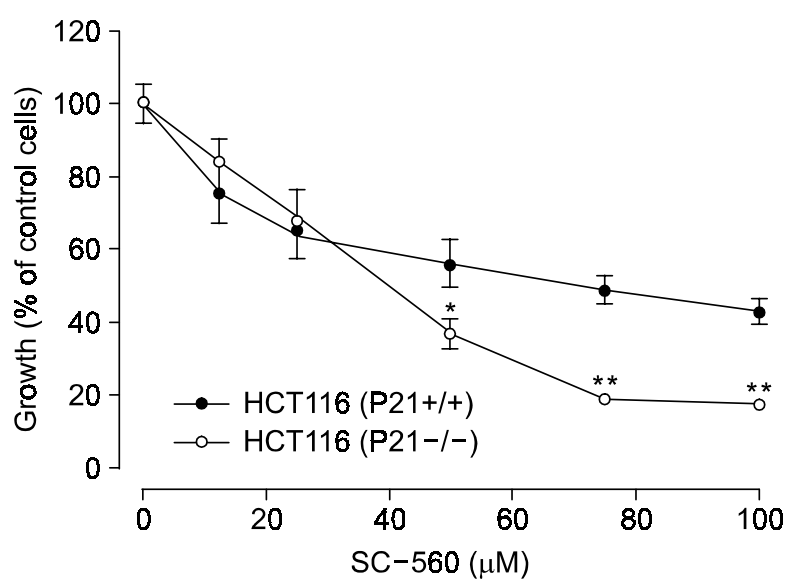

Figure 3. SC-560 more potently inhibited the growth of HCT116 $\left(\mathrm{p} 21^{-1-}\right)$ cells. Following $48 \mathrm{~h}$ treatment with increasing doses of SC-560, cell growth and viability were determined by an MTT assay, as described in the text. Results are mean of three independent experiments and are expressed as percentage growth (mean $\pm S D$ ) relative to control (DMSO)-treated cells. ${ }^{*} P<0.05$ and ${ }^{* *} P<0.005$ by unpaired $t$-test, compared with HCT116 $\left(\mathrm{p} 21^{+/+}\right)$cells treated with same dose of SC-560.

al., 2001; Boonstra and Post, 2004; Kim et al., 2004). Earlier studies including ours have shown that SC-560 acts as a ROS generator to suppress the growth of breast and lung cancer cells (Kundu et al., 2002; Lee et al., submitted). Furthermore, p21CIP1 was shown to be regulated by or regulate the intracellular level of ROS depending on the cellular context and types (Chung et al., 2002; Macip et al., 2002). Therefore, we sought to investigate whether the differential susceptibility of $\mathrm{p} 21^{+/+}$and $\mathrm{p} 21^{-/-}$cells to SC-560 was caused by the difference in ROS generation following SC-560 treatment.

Following $50 \mu \mathrm{M}$ SC-560 treatment for $24 \mathrm{~h}, \mathrm{SC}-$ 560 induced a large increase in the fluorescence of the $\mathrm{H}_{2} \mathrm{O}_{2}$ indicator DCF in both $\mathrm{p} 21^{+/+}$and $\mathrm{p} 21^{-/-}$ cells. It indicates that SC-560 stimulated the intracellular generation of peroxides in HCT116 cells regardless of p21CIP1 expression (Figure 4A). The oxidation of DCFH was already detected after $1 \mathrm{~h}$ of incubation with SC-560 in both cell lines, and was maintained to a similar level over the $24 \mathrm{~h}$ incubation period in both cell lines (Figure 4B). Furthermore, pretreatment of cells with the antioxidant $\alpha$-tocopherol (TOL) significantly reduced SC-560- induced ROS generation, resulting in blockade of growth inhibition (data not shown). These data indicate that p21CIP did not affect the SC-560-induced ROS generation in HCT116 cells, suggesting that the protective effect of p21CIP1 operates downstream or independently from SC-560-induced ROS generation. 


\section{Effect of p21 on the apoptosis induction by SC-560}

We sought to investigate whether the increased sensitivity of $\mathrm{p} 21^{-/-}$cells was caused by their increased susceptibility to apoptosis induction by SC-560. Since apoptosis is generally associated with caspase activation, we examined the activation of caspase by immunoblotting with cell lysates obtained from SC-560 treatment. The processing of procaspase- 3 protein into its catalytically active form (p17/p19) was barely detectable in $\mathrm{p} 21^{+/+}$cells, but apparently observed in $\mathrm{p} 21^{-1-}$ cells by SC-560 treatment (Figure 5A). Furthermore, cell cycle analysis revealed that 50 and $100 \mu \mathrm{M}$ doses of SC-560 increased the percentage of $\mathrm{p} 21^{-1-}$ cells in sub-G1 by 2.0 - and 4.1 -fold, whereas the percentage of $\mathrm{p} 21^{+/ t}$ cells in sub-G1 was increased only by 0.8 - and 1.4-fold in $\mathrm{p}^{1} 1^{+/+}$cells (Figure 5B). In accordance with cell cycle data, apoptosis ELISA assay quantifying the extent of DNA fragmentation revealed that significantly more apoptosis was induced in $\mathrm{p} 21^{-1-}$ cells than in p21 $1^{+/+}$cells (Figure $5 \mathrm{C}$ ). In addition, the morphological changes characteristic of apoptosis, including cell shrinkage and chromatin condensation, was more apparent in $\mathrm{p} 21^{-/-}$cells compared with $\mathrm{p} 21^{1 /+}$ cells after $24 \mathrm{~h}$ incubation with $100 \mu \mathrm{M}$ SC-560 (data not shown). These data suggest that the increased growth suppression by SC-560 in p $21^{-1 /}$ cells was caused by their increased apoptotic susceptibility compared with $\mathrm{p} 21^{+/+}$cells.

p21CIP1, which was initially identified as a protein that regulates the cell cycle, also plays a proapoptotic or an antiapoptotic role in response to antitumor agents depending on the cellular context and the type of agents (Liu et al., 2003). The molecular events underlying the p21CIP1 antiapoptotic effect are not precisely understood, but several steps implicated in the apoptotic process are regulatedby $\mathrm{p} 21 \mathrm{CIP} 1$, including stabilization of p53 (Javelaud and Besancon, 2002) and inhibition of activation of apoptosis signal-regulating kinase 1 , c-Jun N-terminal kinase, and caspase-3 (Shim et al., 1996; Suzuki et al., 1998; Asada et al., 1999). The present results suggest that $\mathrm{p} 21 \mathrm{CIP} 1$ protein plays an important role in protecting cells from apoptosis induction in response to SC-560. This notion is supported by the data that following SC-560 treatment there was less activation of caspase 3 and DNA fragmentation in $\mathrm{p} 21^{+/+}$than in $\mathrm{p} 21^{-/-}$cells. It seems likely that p21CIP1 protected cells from switching on the full force of the cell's apoptotic machinery in response to SC-560 by regulating pathways involved in caspase activation (Gong et al., 2004). With our current data, it remains unclear how p21CIP1 blocked the SC-560-induced apoptosis in HCT116 cells. p21CIP1 might directly inhibit SC-560-induced caspase 3 activation, such as by
$\mathbf{A}$

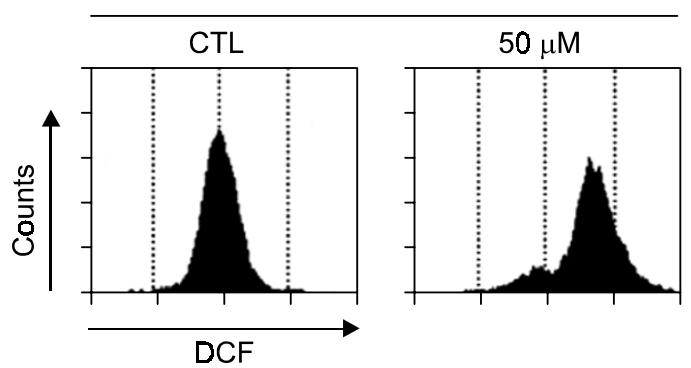

B

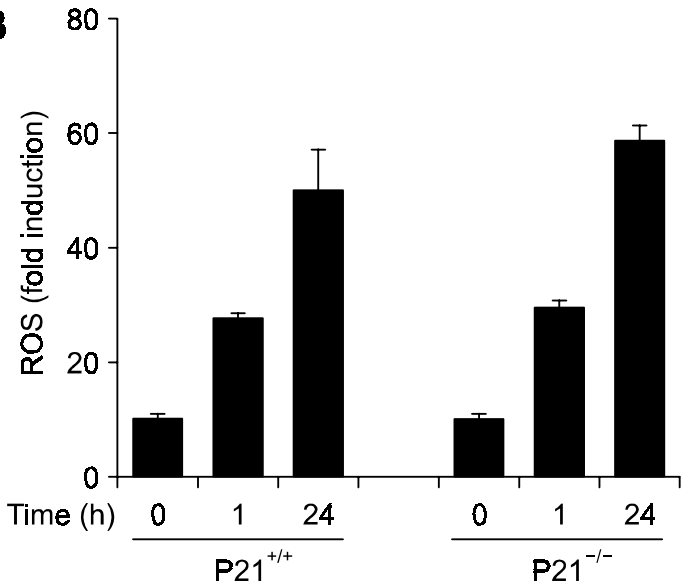

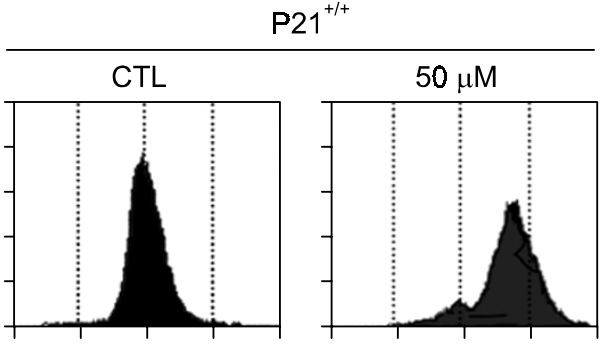

Figure 4. p21CIP1 did not affect the SC-560-induced ROS generation. (A) Representative FACS profile for ROS-induced DCFH oxidation following treatment of cells with $50 \mu \mathrm{M} \mathrm{SC}-560$ for $24 \mathrm{~h}$. (B) SC-560 induced ROS generation in a time-dependent manner in p21 ${ }^{+/+}$and p21 $1^{-1-}$ cells. Cells were treated with vehicle alone or with $100 \mu \mathrm{M} \mathrm{SC}-560$ for 1 and $24 \mathrm{~h}$ prior to ROS determination. ROS data are expressed as the increase in channel fluorescence of treated cells relative to vehicle-treated cells (mean $\pm S D$ ). ROS data represent the mean of at least two independent experiments. 
A

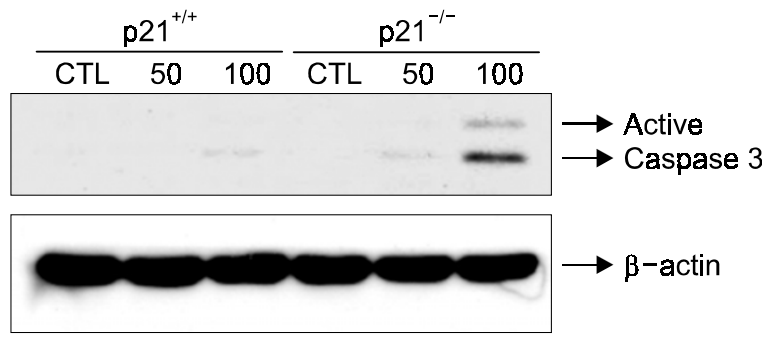

B

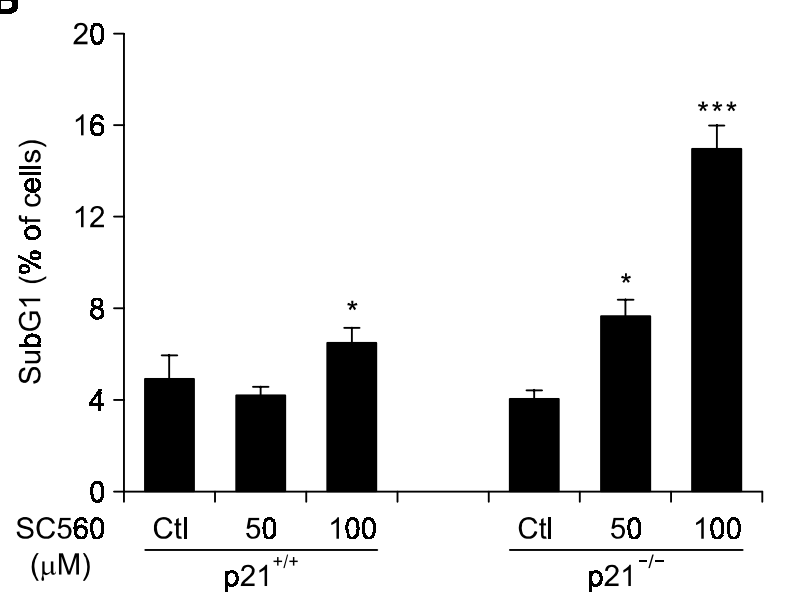

C

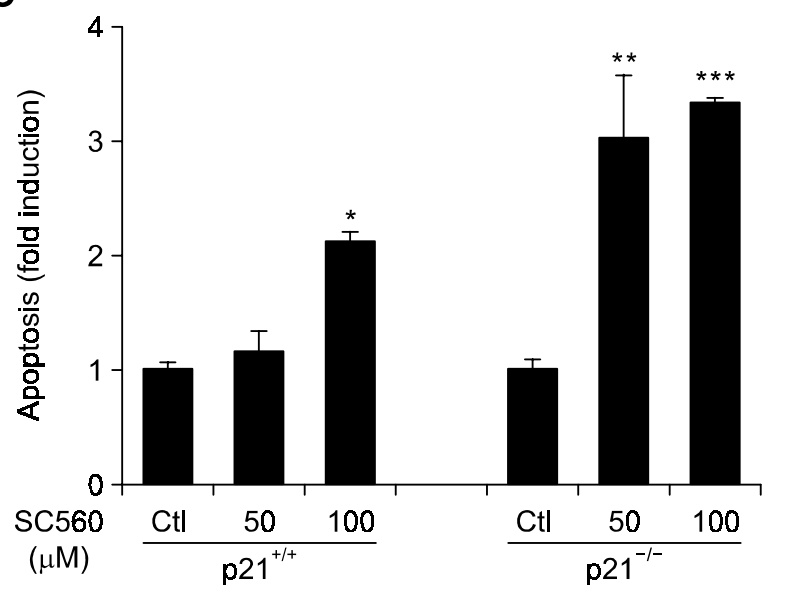

Figure 5. p21CIP1 protected cells from apoptosis in response to SC-560. (A) Western blot analysis for determining activation of caspase-3 in response to SC-560 in the HCT116 isogenic p2 $1^{+/+}$and p21 $1^{-1}$ cells treated with vehicle alone or with 50 or $100 \mu \mathrm{M} \mathrm{SC}-560$ for $24 \mathrm{~h}$. The increase in the apoptotic fraction (B) and histone-associated DNA fragments $(\mathrm{C})$ in the HCT116 isogenic $\mathrm{p} 21^{+/+}$and $\mathrm{p} 21^{1 /+}$ cell cultures, after treating cells with vehicle alone or with 50 or $100 \mu \mathrm{M} \mathrm{SC}-560$ for $24 \mathrm{~h}$. The percentage of apoptotic cells was assessed by calculating the percentage of cells in the sub-G1 phase obtained by flow cytometric analysis of cells stained with propidium iodide, and the DNA fragmentation was determined using a photometric enzyme immunoassay by using Cell Death Detection ELISA ${ }^{\text {plus. }}$ The data shown are mean \pm SD values from triplicate determinations. ${ }^{\star} P<$ $0.05 ;{ }^{* *} P<0.005 ;{ }^{* *} P<0.001$ by unpaired $t$-test, compared with control-treated cells.

forming a complex with caspase-3 and inhibiting its activity (Suzuki et al., 1998). Either p21CIP1 might block the downstream of ROS generation and upstream of caspase activation in response to SC-560.

Combination treatment is a common strategy in cancer therapy to provide more effective anticancer effects, while inducing less toxicity by allowing the use of lower doses of each agent, which may otherwise be toxic at higher doses. Although the SC-560 concentrations used here, as well as in a number of previous studies for investigating the SC-560 effect in vitro, are much higher than the concentrations found in plasma samples from animals after treatment of a single dose of $400-800 \mathrm{mg}$ (Grosch et al., 2001), developing reagents targeting p21CIP1 would help lower the effective dose of SC-560.

\section{Acknowledgement}

This work was supported by a research grant from the National Cancer Center (No. 0310010-3) to S. J. Lim.

\section{References}

Asada M, Yamada T, Ichijo $\mathrm{H}$, Delia D, Miyazono K, Fukumuro K, Mizutani S. Apoptosis inhibitory activity of cytoplasmic p21 (Cip1/WAF1) in monocytic differentiation. Embo J 1999;18:1223-34

Boonstra J, Post JA. Molecular events associated with reactive oxygen species and cell cycle progression in mammalian cells. Gene 2004;337:1-13

Chung YW, Jeong DW, Won JY, Choi EJ, Choi YH, Kim IY. $\mathrm{H}(2) \mathrm{O}(2)$-induced AP-1 activation and its effect on p21 (WAF1/CIP1)-mediated G2/M arrest in a p53-deficient human lung cancer cell. Biochem Biophys Res Commun 2002;293:1248-53

Darzynkiewicz Z, Bruno S, Del Bino G, Gorczyca W, Hotz MA, Lassota P, Traganos F. Features of apoptotic cells 
measured by flow cytometry. Cytometry 1992;13:795-808

Davies NM, Gudde TW, de Leeuw MA. Celecoxib: a new option in the treatment of arthropathies and familial adenomatous polyposis. Expert Opin Pharmacother 2001;2:139-52

De Schepper S, Bruwiere H, Verhulst T, Steller U, Andries L, Wouters W, Janicot M, Arts J, Van Heusden J. Inhibition of histone deacetylases by chlamydocin induces apoptosis and proteasome-mediated degradation of survivin. J Pharmacol Exp Ther 2003;304:881-8

Dotto GP. p21 (WAF1/Cip1): more than a break to the cell cycle? Biochim Biophys Acta 2000;1471:M43-56

Fotedar R, Bendjennat M, Fotedar A. Functional analysis of CDK inhibitor p21WAF1. Methods Mol Biol 2004;81:55-71

Gong X, Wang M, Wu Z, Tashiro SI, Onodera S, Ikejima T. Pseudolaricacid $B$ induces apoptosis via activation of c-Jun $\mathrm{N}$-terminal kinase and caspase-3 in HeLa cells. Exp Mol Med 2004;36:551-6

Gorospe M, Cirielli C, Wang X, Seth P, Capogrossi MC, Holbrook NJ. p21 (Waf1/Cip1) protects against p53-mediated apoptosis of human melanoma cells. Oncogene 1997; 14:929-35

Grosch S, Tegeder I, Niederberger, E, Brautigam L, Geisslinger G. COX-2 independent induction of cell cycle arrest and apoptosis in colon cancer cells by the selective COX-2 inhibitor celecoxib. Faseb J 2001;15:2742-4

Javelaud D, Besancon F. Inactivation of p21WAF1 sensitizes cells to apoptosis via an increase of both p14ARF and p53 levels and an alteration of the Bax/Bcl-2 ratio. J Biol Chem 2002;277:37949-54

Kang HK, Lee E, Pyo H, Lim SJ. Cyclooxygenase-independent down-regulation of multidrug resistance-associated protein-1 expression by celecoxib in human lung cancer cells. Mol Cancer Ther 2005;4:1358-63

Kang YH, Lee E, Choi MK, Ku JL, Kim SH, Park YG, Lim SJ. Role of reactive oxygen species in the induction of apoptosis by alpha-tocopheryl succinate. Int $\mathrm{J}$ Cancer 2004;112:385-92

Kim YS, Jhon DY, Lee KY. Involvement of ROS and JNK1 in selenite-induced apoptosis in Chang liver cells. Exp Mol Med 2004;36:157-64
Kundu N, Smyth MJ, Samsel L, Fulton AM. Cyclooxygenase inhibitors blockcell growth, increase ceramide and inhibit cell cycle. Breast Cancer Res Treat 2002;76:57-64

Liu S, Bishop WR, Liu M. Differential effects of cell cycle regulatory protein p21 (WAF1/Cip1) on apoptosis and sensitivity to cancer chemotherapy. Drug Resist Updat 2003;6: 183-95

Macip S, Igarashi M, Fang L, Chen A, Pan ZQ, Lee SW, Aaronson SA. Inhibition of p21-mediated ROS accumulation can rescue p21-induced senescence. Embo J 2002; 21:2180-8

Prabhu NS, Blagosklonny MV, Zeng YX, Wu GS, Waldman $T$, El-Deiry WS. Suppression of cancer cell growth by adenovirus expressing p21 (WAF1/CIP1) deficient in PCNA interaction. Clin Cancer Res 1996;2:1221-9

Qiao L, McKinstry R, Gupta S, Gilfor D, Windle JJ, Hylemon PB, Grant S, Fisher PB, Dent P. Cyclin kinase inhibitor p21 potentiates bile acid-induced apoptosis in hepatocytes that is dependent on p53. Hepatology 2002; 36:39-48

Qin LF, Ng IO. Exogenous expression of p21 (WAF1/CIP1) exerts cell growth inhibition and enhances sensitivity to cisplatin in hepatoma cells. Cancer Lett 2001;172:7-15

Shim J, Lee H, Park J, Kim H, Choi EJ. A non-enzymatic p21 protein inhibitor of stress-activated protein kinases. Nature 1996;381:804-6

Suzuki A, Tsutomi Y, Akahane K, Araki T, Miura M. Resistance to Fas-mediated apoptosis: activation of caspase 3 is regulated by cell cycle regulator p21WAF1 and IAP gene family ILP. Oncogene 1998;17:931-9

Waldman T, Kinzler KW, Vogelstein B. p21 is necessary for the p53-mediated G1 arrest inhuman cancer cells. Cancer Res 1995;55:5187-90

Wang JA, Fan S, Yuan RQ, Ma YX, Meng Q, Goldberg ID, Rosen EM. Ultraviolet radiation down-regulates expression of the cell-cycle inhibitor p21WAF1/CIP1 in human cancer cells independently of p53. Int J Radiat Biol 1999; 75:301-16

Zang Y, Beard RL, Chandraratna RA, Kang JX. Evidence of a lysosomal pathway for apoptosis induced by the synthetic retinoid CD437 in human leukemia HL-60 cells. Cell Death Differ 2001;8:477-85 